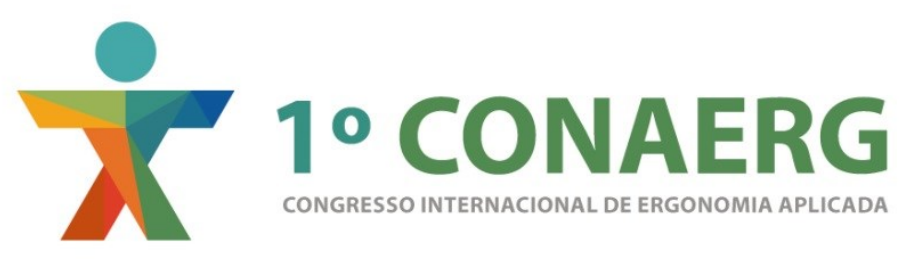

\title{
CONCEPÇÃO DE CALÇADAS À LUZ DA NBR 9050 INTERPRETAÇÕES EQUIVOCADAS DAS RECOMENDAÇÕES DA NORMA
}

\author{
Diva Carolina A. de Assis (1); \\ Alexandre Márcio Toledo (2) \\ (1) Instituto Federal de Alagoas, Especialista em Iluminação e Design de Interiores \\ e-mail: divacarolina.arq@gmail.com \\ (2) Universidade Federal de Alagoas, Doutor em Engenharia Civil \\ e-mail: alexandre.toledo@fau.ufal.br
}

\begin{abstract}
RESUMO
A NBR 9050/2015 estabelece as condições de acessibilidade; porém, mesmo com a facilidade de obtenção à norma, os projetistas e o poder público ainda cometem equívocos quanto à sua aplicação no espaço urbano. Esse artigo tem como objetivo analisar a concepção das calçadas na cidade de Maceió/AL, à luz dos preceitos dessa norma. Selecionaram-se para estudo seis calçadas de dois bairros da baixada litorânea da cidade. Perceberam-se interpretações errôneas da aplicação da norma, criando situações confusas que podem induzir os usuários ao erro e submetê-los a riscos. Constata-se a necessidade de aprofundar as razões para os equívocos observados.
\end{abstract}

\begin{abstract}
The NBR 9050/2015 establishes the conditions of access; but even with the ease of access to the standard, designers and the public can also make mistakes in their application in the urban space. This paper aims to analyze the design of sidewalks in the city of Maceió / AL, in the light of the provisions of this standard. Selected to study six sidewalks of two neighborhoods in the coastal lowlands of the city. They realized to misinterpretations of the application of the standard, creating confusing situations that can induce users to error and subject them to risks. Notes the need to deepen the reasons for the observed misconceptions.
\end{abstract}

\section{INTRODUÇÃO}

A NBR 9050 - Acessibilidade a edificações, mobiliário, espaços e equipamentos urbanos é uma das poucas normas da Associação Brasileira de Normas Técnicas - ABNT, que tem força de lei, dada pela Lei Federal 10.098/2000, a qual foi regulamentada pelo Decreto Federal 5.296/2004. Considerando a relevância dessa e das demais normas referentes à acessibilidade, o Ministério Público Federal celebrou um acordo com a ABNT, em 2004, para que elas não fossem comercializadas, como as demais normas que são ofertadas pela ABNT, mas divulgadas pela Internet ou pelo Diário Oficial, permitindo o acesso amplo e irrestrito a qualquer pessoa. 
É na cidade onde os indivíduos adquirem a condição de cidadãos, com direitos e deveres. Dentre os direitos está o de ir e vir aonde quer que se queira. Porém, esse direito é cerceado quando as condições físicas do passeio público não estão de acordo com as suas necessidades físicas.

Os seres humanos possuem características distintas e necessidades específicas. $O$ conceito de acessibilidade não se restringe a pessoas com algum tipo de deficiência. Ele vai além, englobando as mais diversas condições sensoriais e físicas. Um indivíduo pode ter uma mobilidade reduzida resultante de algo transitório, como uma perna quebrada, o uso de um carrinho de bebê ou de compras, uma gravidez.

A última revisão da NBR 9050 englobou os sete princípios do Desenho Universal, cujo conceito surgiu nos Estados Unidos, na década de 1960, como consequência das reinvindicações políticas de dois segmentos sociais diversos: o movimento de pessoas com deficiência e da iniciativa de alguns arquitetos, urbanistas e designers que buscavam uma maior democratização dos valores e uma visão mais ampla na concepção dos projetos. (CAMBIAGHI, 2007).

Um projeto pode seguir, estritamente, as normas técnicas e ser acessível, mas isso não é premissa de um projeto confortável ao usuário. Com a aplicação dos princípios do Desenho Universal, que é uma filosofia de projeto, a percepção e o olhar do projetista serão mais amplos à sociedade.

Projetistas e setores de fiscalização não apreendem bem o teor apresentado por essa norma e cometem alguns equívocos na hora da projetação. Isso pode ser verificado ao percorrer as ruas da cidade de Maceió com um olhar mais focado para a acessibilidade urbana.

Maceió vem, já há alguns anos, alterando suas calçadas com o principal objetivo de adequála às normas de acessibilidade arquitetônica. Uma tentativa que, muitas vezes é frustrada pela incorreta leitura da norma.

Essas características são relevantes visto que, para novas construções ou reformas, o projeto precisa passar por análise da prefeitura, a qual busca sempre avaliar as características construtivas das calçadas.

O presente artigo tem como objetivo analisar a concepção das calçadas em Maceió/AL, à luz do conteúdo atualizado da NBR 9050 e do conceito de Desenho Universal.

\section{PRINCIPAIS CONCEITOS}

\subsection{Os Princípios do Desenho Universal}

O Desenho Universal, como já dito, é uma filosofia de projeto. Não é uma forma de projetar para pessoas com deficiência, mas sim, para todas as pessoas quanto possível for, de uma forma geral, seja ela criança, obeso, mulher grávida, idoso, etc. sem distinção entre sexo, idade, raça ou cultura.

De acordo com a NBR 9050/2015, acessibilidade é a possibilidade e condição de alcance, percepção e entendimento para utilização, com segurança e autonomia, de espaços, mobiliários, equipamentos urbanos, edificações, transportes, informação e comunicação, 
inclusive seus sistemas e tecnologias, bem como outros serviços e instalações abertos ao público, de uso público ou privado de uso coletivo, tanto na zona urbana como na rural, por pessoa com deficiência ou mobilidade reduzida.

O Desenho Universal tem, segundo a NBR 9050/2015, a seguinte definição: é a concepção de produtos, ambientes, programas e serviços a serem utilizados por todas as pessoas, sem necessidade de adaptação ou projeto específico, incluindo os recursos de tecnologia assistiva.

1. Uso equitativo: Possibilidade de uso por pessoas de diversas capacidades;

2. Uso flexível: Ser adaptável para diversas necessidades ou preferências;

3. Uso simples e intuitivo: eliminar complexidades desnecessárias, dispondo de informações facilmente perceptíveis em ordem de importância;

4. Informação perceptível: comunicação eficaz independendo de condições ambientais ou de capacidade sensorial;

5. Tolerância a erros: Minimizar o risco e as consequências de ações acidentais.

6. Baixo esforço físico: Uso eficiente e confortável com o mínimo de fadiga;

7. Tamanho e espaço para aproximação e uso: oferecer espaço e dimensões apropriadas ao uso, independentemente do tamanho ou da mobilidade do usuário.

\subsection{As versões da NBR 9050}

A NBR 9050 surgiu no ano de 1985 e foi publicada pela Associação Brasileira de Normas Técnicas - órgão competente, no Brasil, para publicação de normas técnicas. As normas técnicas da ABNT surgem por meio dos chamados Comitês Brasileiros (CB), os quais são órgãos responsáveis pela coordenação, planejamento e execução das atividades de normalização técnica.

Dentre os mais diversos comitês da ABNT, o Comitê Brasileiro de Acessibilidade, CB-40, é responsável pela

Normalização no campo de acessibilidade atendendo aos preceitos de desenho universal, estabelecendo requisitos que sejam adotados em edificações, espaços, mobiliários e equipamentos urbanos, meios de transporte, meios de comunicação de qualquer natureza, e seus acessórios, para que possam ser utilizados por pessoas portadoras de deficiência.

Desse comitê foi que surgiu a NBR 9050 - Acessibilidade a edificações, mobiliário, espaços e equipamentos urbanos. Desde a sua primeira publicação a norma já foi revisada três vezes: em 1994, em 2004 e a última revisão ocorreu em 2015.

Na última revisão dessa norma, alguns itens referentes à projetação de calçadas foram incluídos, como a separação da calçada em três faixas: de acesso, de pedestres e de serviço, de acordo com a sua largura. Essa diferenciação de faixas deve vir com texturas e 
cores distintas a fim de proporcionar uma melhor percepção ao usuário cego ou com baixa visão.

Deve-se considerar que a revisão da norma foi publicada em outubro de 2015. De uma forma geral não houve alterações nas normativas referentes às calçadas. Houve sim, acréscimo de informações que, de agora em diante, deverá beneficiar um maior número de usuários, como a separação da calçada em faixas diferenciadas por uso.

No entanto, outros tantos itens foram suprimidos, mais precisamente, parte dos itens referentes à sinalização tátil de piso. Isso porque o CB-40 tinha, à época, a pretensão de publicar uma nova norma técnica referente à explanação do correto uso do piso tátil de alerta e direcional. Essa norma só foi publicada em junho deste ano, ficando uma lacuna de cerca de 08 (oito) meses.

\section{METODOLOGIA}

Selecionaram-se para estudo dois bairros, Ponta Verde e Jatiúca, ambos localizados na baixada litorânea da cidade de Maceió/AL (Fig. 1) e seis calçadas (Fig. 2), situadas em pontos estratégicos.

Os bairros Ponta Verde e Jatiúca apresentam alto índice de adensamento e verticalização dos edifícios e são considerados bairros nobres na cidade. Neles se observa a crescente e constante construção de novos edifícios residenciais, bem como de novos estabelecimentos comerciais.

Muitos são os critérios a serem observados na verificação da concepção de condições de uso de uma calçada, no entanto, esse trabalho irá se ater às recomendações da NBR 9050. As análises desse estudo focarão na NBR9050, em situações existentes na publicação de 2004 visto que, pelo curto tempo em que a mesma foi revisada, cerca de 08 (oito) meses, existirão casos em que o projetista se baseou em informações presentes na versão do ano de 2004 a qual foi balizadora para construção da maioria das calçadas estudadas.

Para isso segue alguns itens, presentes nela, e que foram alvo de investigação.

- A norma, em sua antiga versão, impunha que a aplicação do piso tátil de alerta deveria acontecer perpendicularmente ao sentido de deslocamento nas seguintes situações: a) obstáculos suspensos; b) rebaixamento de calçadas; c) início e término de escadas ou rampas; d) junto à porta de elevadores; e) junto a desníveis como plataformas, palcos, vãos. Na nova versão esse item foi suprimido;

- Também NBR9050/2004 estabelecia que objetos suspensos entre a altura de 0,60m e 2,10m deveriam ser sinalizados com piso tátil de alerta em todo seu perímetro, mas com uma distância de $0,60 \mathrm{~m}$ da projeção do objeto suspenso;

- Outro item retirado na revisão é o da sinalização de piso das rampas. A NBR 9050/2004 citava que a sinalização pode ser contornando a rampa, ou colocando uma faixa de piso de alerta, na transversal da rampa, distando $50 \mathrm{~cm}$ da sarjeta.

O estudo analisará primeiro a aplicação dos pisos táteis direcionais e, posteriormente, os pisos táteis de alerta. 
Figura 1 - localização dos Bairros Jatiúca e Ponta Verde na Malha Urbana

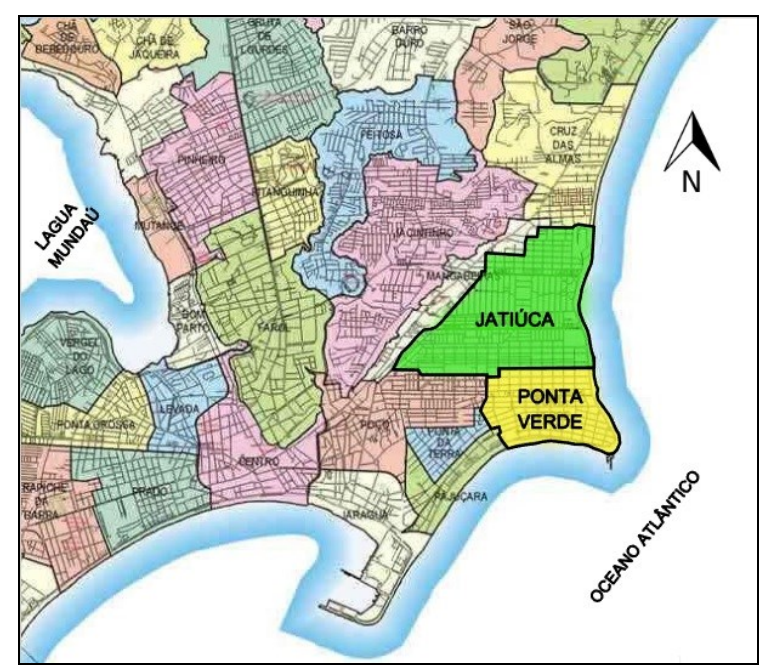

Fonte: Adaptado de

http://www.bairrosdemaceio.net, 2016
Figura 2 - Localização das Calçadas nos Bairros Jatiúca e Ponta Verde

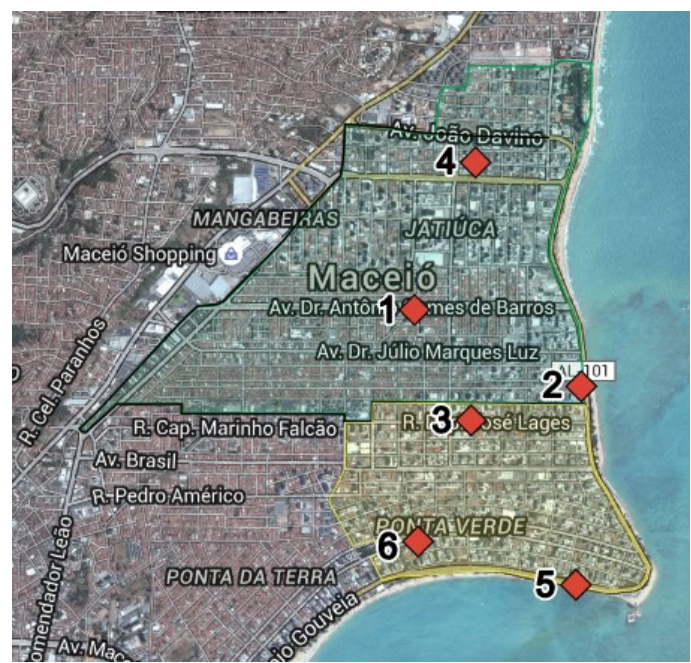

Fonte: Adaptado de

www.google.com.br/maps, 2016

\section{ANÁLISES DAS CALÇADAS}

Observou-se que a maioria das seis calçadas selecionadas não apresenta interpretação correta dos princípios estabelecidos pela NBR 9050, no entanto, algumas seguem corretamente as normativas técnicas.

\subsection{Calçada 1}

Nesta calçada (Fig. 2), situada em frente a um edifício residencial em construção, no bairro Jatiúca, pode-se observar que já foi projetada seguindo as recomendações da NBR 9050 em sua última publicação, com uma faixa de serviço de 75 centímetros de largura, com cor e textura diferenciadas da faixa de passeio.

Figura 2 - Calçada do Edifício Residencial em Construção

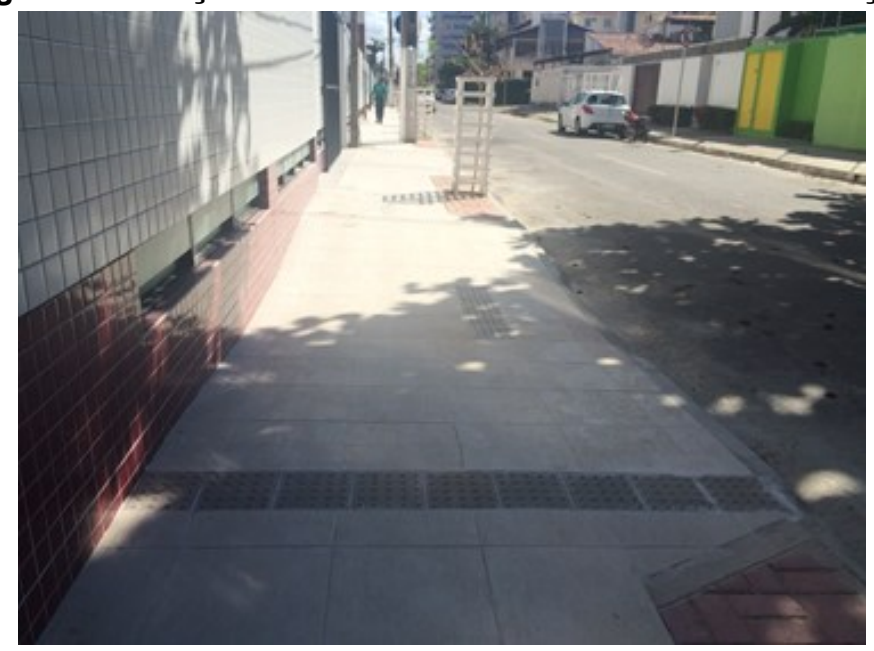

Fonte: Acervo da autora, 2016 
Apesar de não ser uma calçada tão estreita, já que ela possui 2 (dois) metros de largura, o projetista optou pelo rebaixamento da calçada, colocando o piso de alerta no início do desnível, em ambos os lados.

Nesse outro ponto pode-se observar que a rampa foi corretamente sinalizada (Fig. 3), com uma faixa de piso de alerta a 50 centímetros da sarjeta, e com uma linha de piso tátil direcional que vai até o muro. Este passando a ser a linha guia para um usuário cego. Todo o conjunto já ficou de acordo com a NBR 9050/2015, a mais recente revisão da norma.

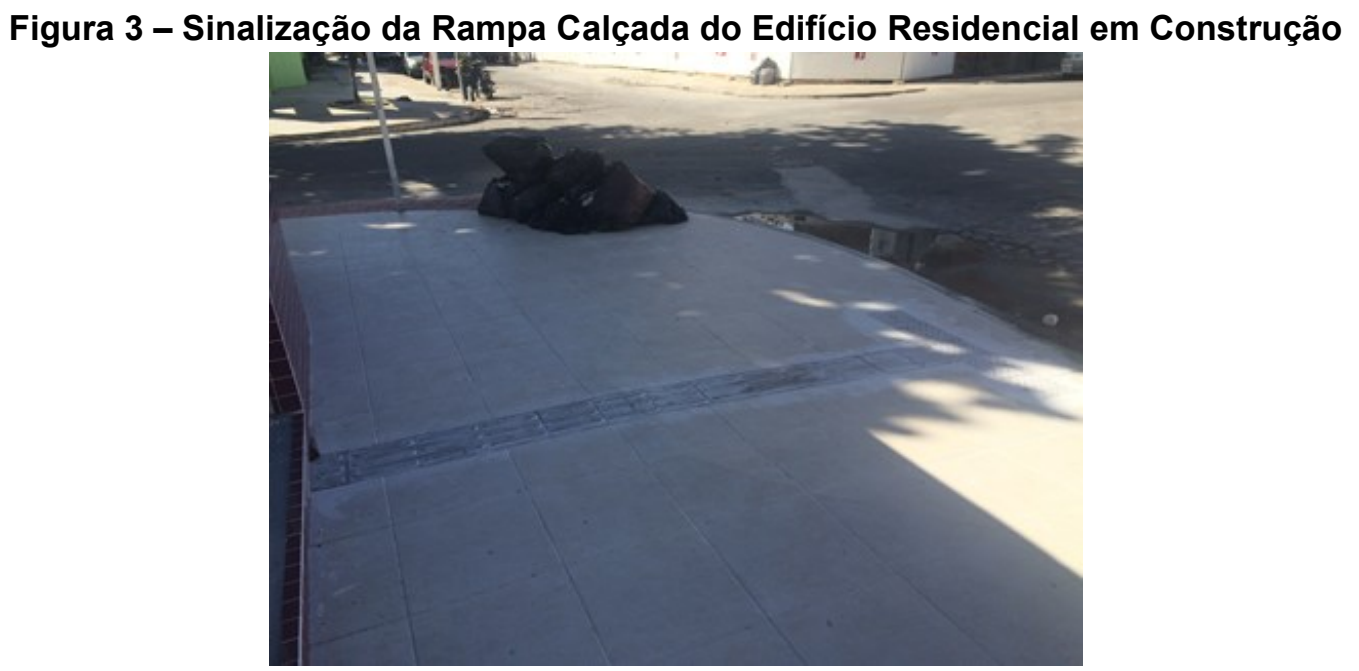

Fonte: Acervo da autora, 2016

Ótimo exemplo de calçada. Os pisos de alerta colocados corretamente nas rampas existentes e o piso direcional aplicado onde há necessidade que, nesse caso, liga o rebaixamento da calçada à linha guia mais próxima, sendo o muro.

\subsection{Calçada 2}

Nesta calçada (Fig. 4), situada em frente ao Edifício Comercial The Square, no bairro Jatiúca, percebe-se o piso tátil de alerta em torno de um arbusto de copa alta. Neste caso, a copa está abaixo de $2,10 \mathrm{~m}$, justificando a demarcação, porém, esta não 60 centímetros da projeção da copa no chão.

Figura 4 - Calçada do Edifício Comercial The Square

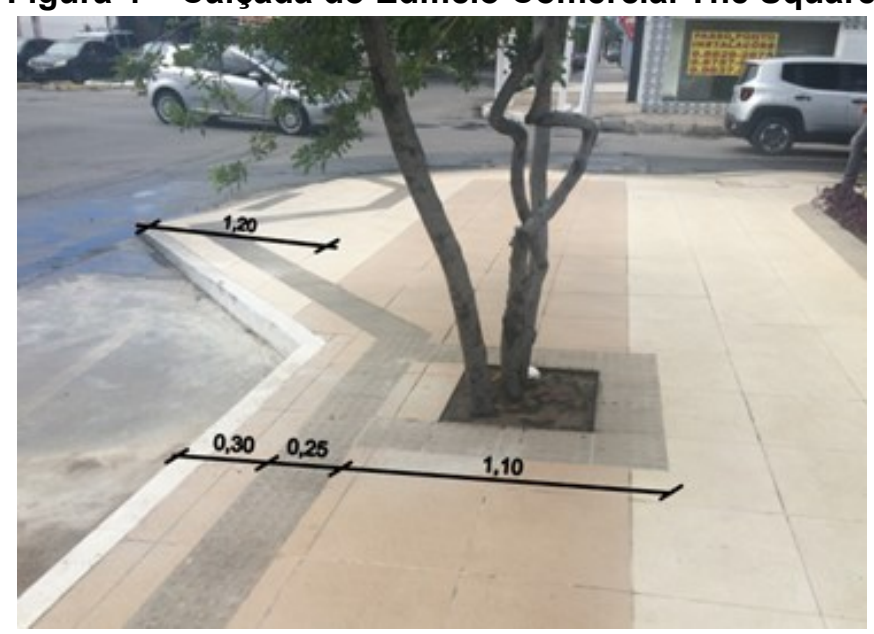

Fonte: Acervo da autora, 2016 
Pode-se notar, também, a instalação do piso de alerta 30 centímetros do meio fio. Ou seja, nesse caso, a aplicação do piso não se enquadra em nenhuma dessas situações existentes em norma, não justificando, portanto, a sua utilização.

Noutro ponto da calçada (Fig. 5), verifica-se o piso de alerta contornando um canteiro. Pelos casos exigidos na norma de 2004, não há nenhuma necessidade da utilização desse piso nesse contexto. Risco de indução do usuário cego ao erro.

Figura 5 - Canteiro da Calçada do Edifício Comercial The Square

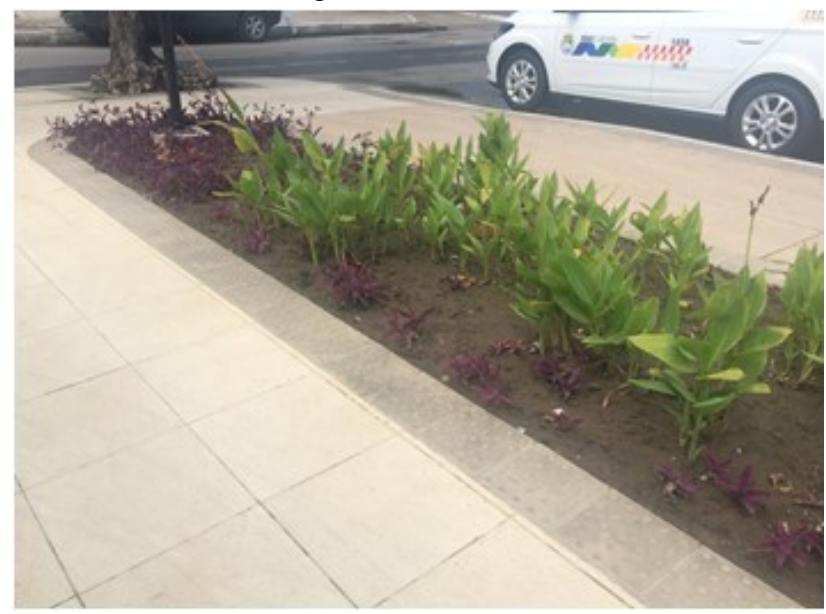

Fonte: Acervo da autora, 2016

\subsection{Calçada 3}

Esta calçada, situada em frente ao Edifício Residencial Palazzo Firenze, no bairro Jatiúca, apresenta uma proposta de piso de alerta margeando o meio fio e seguindo atravessando a rampa (Fig. 6). Esse traçado não é condizente com o texto da norma de 2004.

Supondo-se que o projetista imaginou uma separação de faixas, como a faixa de serviço, onde é instalado o mobiliário urbano não deveria ter sido feito com esse piso, visto que ele tem uso específico, de acordo com a norma técnica que, neste caso, não é para essa função.

Figura 6 - Calçada do Edifício Residencial Palazzo Firenze

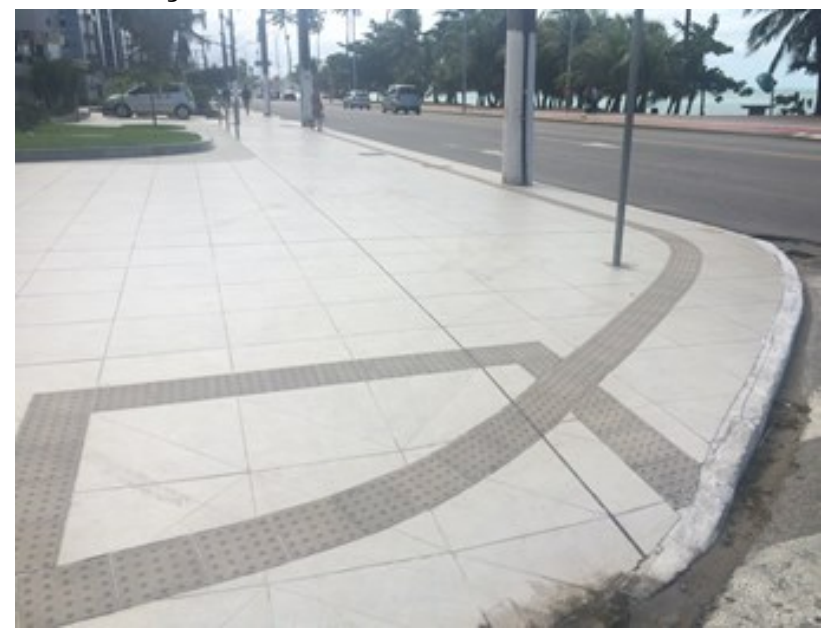

Fonte: Acervo da autora, 2016 
A colocação do piso tátil de alerta nesta rampa poderia acontecer apenas na sua linha limítrofe, dispensando a faixa ao centro dela que, neste caso, ainda está inclinada, não podendo ser desta forma. A faixa deve ser reta e distar 50 centímetros da tarjeta, sendo paralela a esta.

A piso tátil direcional não foi aplicado mesmo sendo necessário já que esta é uma calçada de quase 5 metros de largura.

\subsection{Calçada 4}

No caso desta calçada situada em frente a um edifício comercial em construção, no bairro Ponta Verde, há a mudança de direção e, nela, deveriam existir, pelo menos, quatro peças de piso tátil de alerta, porém só há uma. A NBR 9050 recomenda as quatro peças visto que, a pessoa cega, usuária da bengala longa, não consegue rastrear uma área tão pequena com sua bengala e acaba por "perder-se" do caminho.

Figura 7 - Mudança de Direção na Calçada do Edifício Comercial em Construção
Figura 8 - Proposta de Mudança de Direção na Calçada do Edifício Comercial em Construção

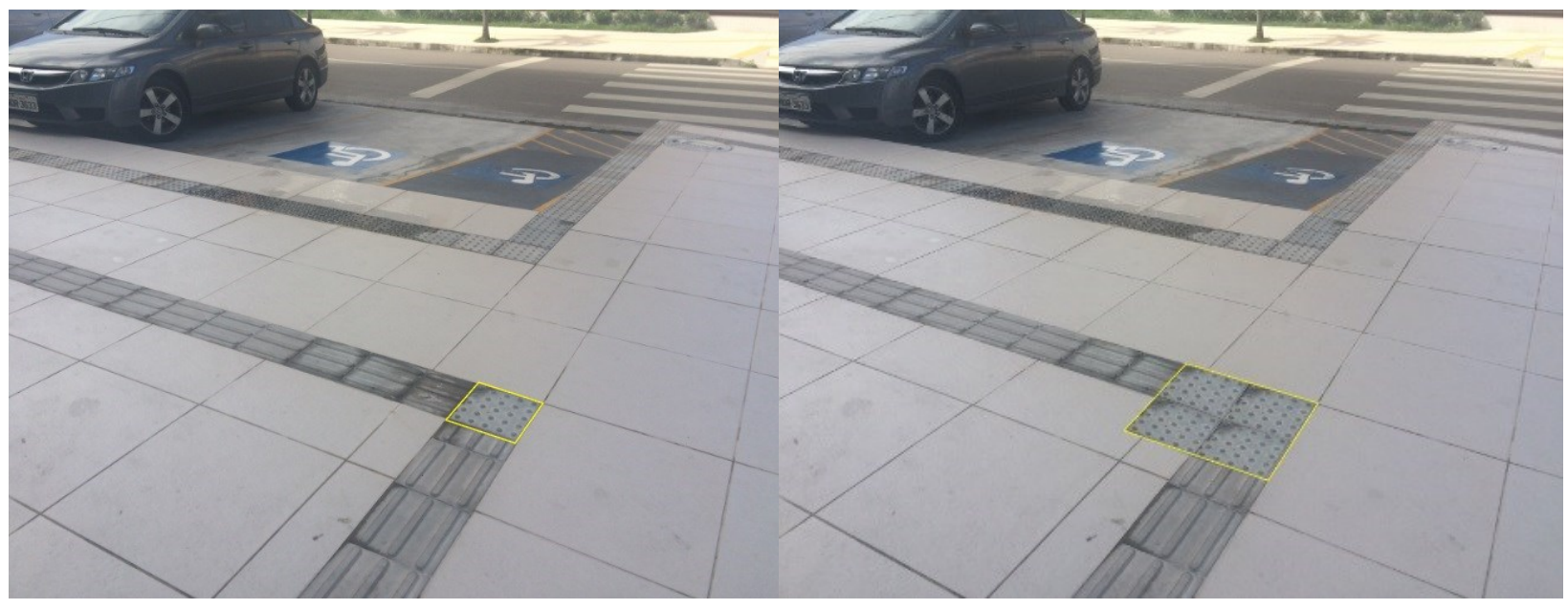

Fonte: Acervo da autora, 2016

Fonte: Acervo da autora, 2016

Observa-se o correto uso do piso tátil direcional. Trata-se de uma calçada de 3 (três) metros de largura, justificando a aplicação do piso no centro do percurso. Porém, o piso de alerta na borda da calçada não se justifica visto que o mesmo só deve ser usado em casos específicos, como já mencionado, e esse não seria nenhum dos casos. 


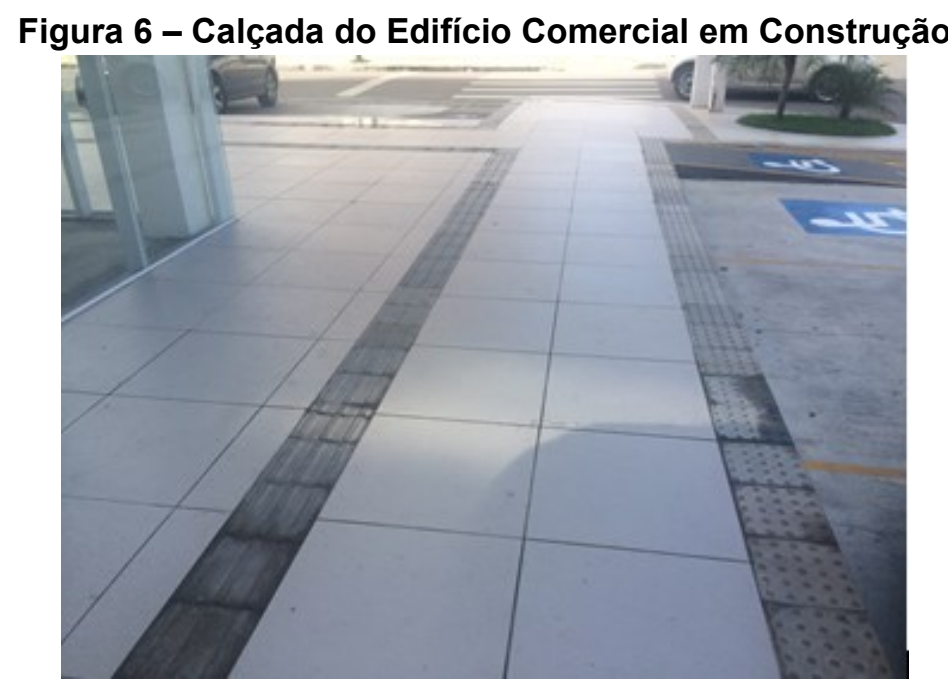

Fonte: Acervo da autora, 2016

Outra questão observada nessa calçada foi o material utilizado que, como visto in loco, não é antiderrapante, conforme solicita a NBR 9050, podendo causar acidentes aos pedestres em dias de chuva.

\subsection{Calçada 5}

A calçada situada em frente à Farmácia Permanente (Fig. 9), no bairro Ponta Verde, é um péssimo exemplo de calçada. Observa-se um estacionamento com guia rebaixada junto à pista de rolamento e a calçada ao lado esquerdo. Existe uma linha de piso tátil de alerta à margem da rua. Fato desnecessário visto que, pela configuração da situação, não se trata de calçada, não há risco de queda, nem nenhum outro item existente na NBR 9050.

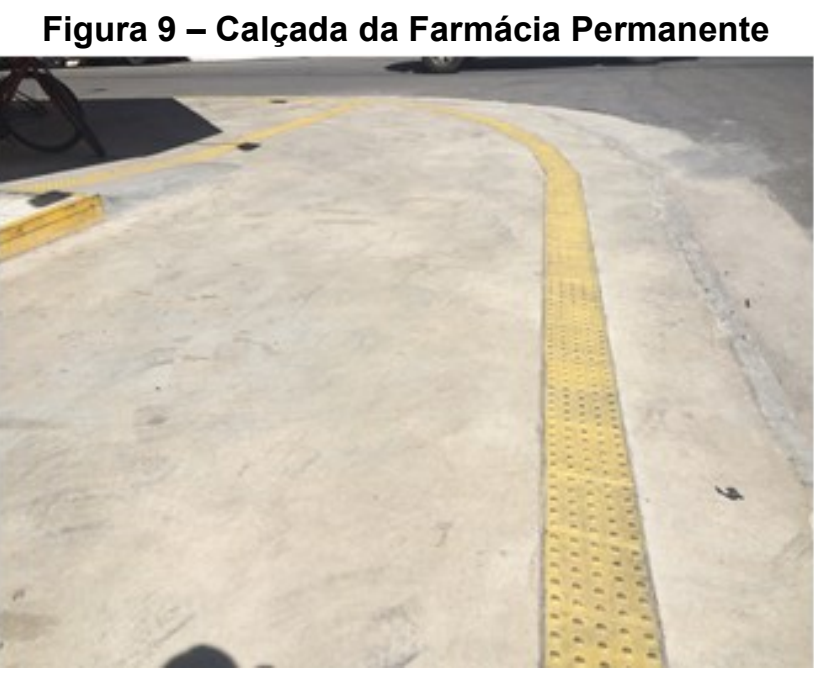

Fonte: Acervo da autora, 2016

Olhando por outro ângulo (Fig. 10), percebe-se que, aparentemente, o piso de alerta foi usado com intuito de direcionar e não de alertar sobre algo, já que ele segue da sarjeta até o final da rampa. A calçada que se inicia após a rampa tem 80 centímetros de largura é muito estreita e fora do padrão da NBR 9050 que solicita, no mínimo, 1,20 metros. 
Figura 10 - Piso de Alerta Calçada da Farmácia Permanente

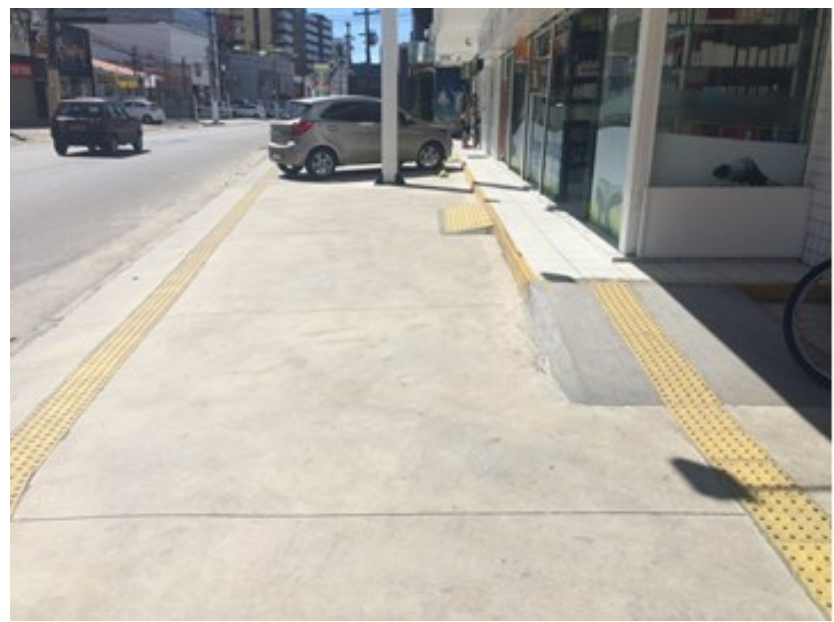

Fonte: Acervo da autora, 2016

Mas essa é uma prática muito comum observada durante esse estudo. Com frequência o piso tátil de alerta é aplicado no intuito de direcionar. A fiscalização da cidade é omissa e, por vezes, informa incorretamente como deve ser a projetação dos pisos táteis.

\subsection{Calçada 6}

$\mathrm{Na}$ calçada da orla da praia de Ponta Verde (Fig. 11), observa-se a faixa de serviço diferenciada em cor e textura da faixa de passeio e, a ciclovia em nível diferenciado e o meio fio que os separa pintado em cor contrastante. Ótima solução dentro dos padrões da NBR 9050.

Apesar da construção desta calçada ter mais de 10 anos, foi uma solução adotada corretamente que, hoje, de acordo com as novas normativas, se insere de forma positiva, sendo exemplo correto da nova leitura da norma.

Figura 11 - Calçada da Orla da Praia de Ponta Verde

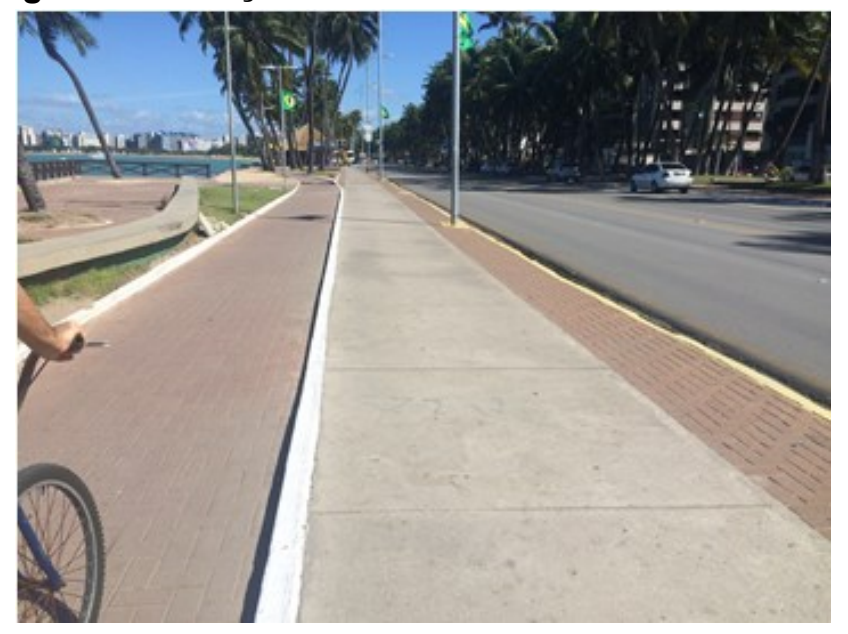

Fonte: Acervo da autora, 2016

\section{CONCLUSÕES}

A pesquisa buscou analisar as situações mais típicas existentes nos bairros de Jatiúca e Ponta Verde, considerando apenas as amostras que claramente buscavam se enquadrar na 
NBR 9050, na versão de 2004 e, em alguns casos, já ponderando as inclusões de informações presentes na sua revisão de 2015, sem considerar as tantas amostras de calçadas que não possuem nenhum tipo de tratamento voltado à acessibilidade.

Percebe-se nos pontos escolhidos que, por muitas vezes existe uma interpretação errônea da leitura do texto da NBR 9050, criando situações confusas que, além de não estarem dentro dos padrões normativos podem, facilmente, induzir o usuário ao erro bem como submetê-lo a riscos, como quedas e desvio de rotas como no caso do usuário cego, por exemplo.

Faz-se necessário um levantamento do porquê dessas situações serem tão repetitivas, no entanto, pode-se sugerir alguns motivos como as faculdades não possuírem na sua grade matéria específica sobre essa temática; pode haver uma cobrança por parte dos órgãos fiscalizadores em situações diversas da norma, induzindo o profissional ao erro; pode ser um descuido dos profissionais na hora de estudar a legislação. Enfim, essas são hipótese as quais necessitariam de um outro estudo para encontrar possíveis respostas.

As situações encontradas nas amostras ora apontadas repetem-se em outros locais, não sendo esses exemplos isolados nem exaustivos.

É sabido que para construções de novas calçadas o projeto deve ser aprovado em órgão competente por equipe técnica. Porém, a frequente troca de usos dos pisos táteis sugere que as soluções adotadas são projetadas e analisadas por profissionais que não apreendem corretamente o uso desses pisos.

Com a publicação de uma norma técnica exclusiva para projetação de pisos táteis em junho do corrente ano, a NBR 16537/2016, muitas questões omissas nas edições da NBR 9050, são esclarecidas facilitando a compreensão dos intuitos normativos.

Constata-se a necessidade de aprofundar as razões para os equívocos observados.

\section{REFERÊNCIAS BIBLIOGRÁFICAS}

ASSOCIAÇÃO BRASILEIRA DE NORMAS TÉCNICAS (ABNT). NBR 9050: Acessibilidade a edificações, mobiliário, espaços e equipamentos urbanos. 2004. Rio de Janeiro, 2004.

ASSOCIAÇÃO BRASILEIRA DE NORMAS TÉCNICAS (ABNT). NBR 9050: Acessibilidade a edificações, mobiliário, espaços e equipamentos urbanos. 2015. Rio de Janeiro, 2015.

ASSOCIAÇÃO BRASILEIRA DE NORMAS TÉCNICAS (ABNT). NBR 16537: Acessibilidade - Sinalização tátil no piso - Diretrizes para elaboração de projetos e instalação. 2016. Rio de Janeiro, 2016.

BRASIL. Decreto 5.296 de 02 de dezembro de 2004. Regulamenta as Leis nos 10.048 , de 8 de novembro de 2000, que dá prioridade de atendimento às pessoas que especifica, e 10.098, de 19 de dezembro de 2000, que estabelece normas gerais e critérios básicos para a promoção da acessibilidade das pessoas portadoras de deficiência ou com mobilidade reduzida, e dá outras providências. Disponível em: 
<http://www.planalto.gov.br/ccivil_03/ato2004-2006/2004/decreto/d5296.htm>. Acessado em: 25 de junho de 2016.

CAMBIAGHI, S. Desenho Universal. 1. ed. São Paulo: Editora Senac, 2007.

LAMOUNIER, L.P. Acessibilidade em calçadas. Câmara dos deputados, 2015. Disponível em: $\quad<$ http://www2.camara.leg.br/documentos-e-pesquisa/publicacoes/estnottec/areas-daconle/tema14/2015_9203-acessibilidade-em-calcadas-ludimila-lamounier> Acesso em 24 de junho de 2016.

LEITE, F. P. O Município acessível à pessoa portadora de deficiência. 1. ed. São Paulo: RCS, 2007.

ROSSO, S. M. Arquitetura Inclusiva. Disponível em: <http://au.pini.com.br/arquiteturaurbanismo/180/artigo128101-1.aspx> Acesso em 24 de julho de 2016. 